\title{
Rap nacional: a juventude negra e a experiência poético- musical em sala de aula
}

\author{
[ National rap: black youth and the musical poetical experience inside classroom
}

\section{Ana Claudia Florindo Fernandes'}

\section{Raquel Martins ${ }^{2}$}

\section{Rosângela Paulino de Oliveira ${ }^{3}$}

RESUMO - Este artigo se destina à reflexão acerca da utilização do rap nacional no ambiente escolar a partir de sua estética e discurso, como meio de problematizar junto aos jovens a história da escravidão do Brasil, bem como a disseminação e perpetuação do preconceito racial na sociedade brasileira. Serão abordadas algumas experiências realizadas com adolescentes em oficinas baseadas no rap, referentes a pesquisas de campo que fizeram parte de um Projeto de Pesquisa de Políticas Públicas. Será discutido em que medida o rap, constituído de múltiplas linguagens, tais como a oralidade, a música e a expressão corporal, pode contribuir para os processos de formação do jovem afrodescendente e morador da periferia de São Paulo e para a afirmação da sua identidade pela via do reconhecimento. PALAVRAS-CHAVE - Adolescente; afrodescendente; rap nacional; oralidade; estética; reconhecimento. · ABSTRACT - This article is intended for thinking about the use of national rap at the school environment from its aesthetic and speech as a means to discuss with young people the history of slavery in Brazil, as well as the spread and perpetuation of racial prejudice in Brazilian society. It will englobe some experiments conducted amidst adolescents in workshops based on rap, regarding to field studies that were part of a Research Project for Public Policy in the area of Education. It will be discussed to what extent the rap, consisting of multiple languages, such as oral, music and body language, can contribute to the youth's learning processes of African descendants, resident in the outskirts of Sao Paulo, and how it contributes to build their identities through recognition. • KEYWORDS . Teenager; African descent; national rap; orality; aesthetics; recognition.

Recebido em 20 de março de 2015

Aprovado em I4 de julho de 2016

FERNANDES, Ana Claudia Florindo; MARTINS, Raquel; OLIVEIRA, Rosângela Paulino de. Rap nacional: a juventude negra e a experiência poético-musical em sala de aula. Revista do Instituto de Estudos Brasileiros, Brasil, n. 64, p. I83-200, ago. 2016.

DOI: http://dx.doi.org/Io.II606/issn.23I6-90IX.voi64pI83-200

I Universidade de São Paulo (USP, São Paulo, SP, Brasil).

2 Universidade de São Paulo (USP, São Paulo, SP, Brasil).

3 Universidade Nove de Julho (Uninove, São Paulo, SP, Brasil). 


\section{INTRODUÇÃo}

O presente artigo propõe reflexões acerca da utilização do rap nacional no ambiente escolar, como meio de expressão da juventude negra, a partir de sua estética e discurso. Dimensões que, por sua vez, são traduzidas por meio de múltiplas linguagens, como a música, a oralidade e a performance corporal, que expressam o anseio de afirmação da identidade do jovem afrodescendente e morador de periferia. Será discutido em que medida o rap, constituído por essa gama de linguagens originadas em territórios urbanos, pode contribuir para os processos de formação do jovem que sofre humilhação social e moral por ser negro. Uma formação que problematize, junto ao aluno, a afirmação e a preservação de sua identidade por meio da valorização de suas origens étnicas e sociais. Diante do aumento da violência urbana, que mata milhares de jovens afrodescendentes ou os põe sob o jugo do sistema penitenciário, é necessária e urgente a discussão, nos processos de formação, de questões evitadas ou mal compreendidas, referentes à discriminação racial entranhada na sociedade brasileira, que ganha novos contornos na atualidade.

Considerando a necessidade de inserir criticamente a cultura do negro nos currículos escolares e tomar seus conhecimentos como a base do ensino, foram realizadas pesquisas de campo por meio de oficinas de rap, com o intuito de desenvolver a percepção dos alunos pela via das linguagens que constituem esse gênero musical juvenil, especificamente, a estética musical e a oralidade. Serão descritas e analisadas neste artigo duas dessas oficinas - uma destinada à experimentação do rap aliada ao letramento, e outra, à estética musical. Desse modo, cada pesquisadora buscou, a partir de sua área de atuação, experimentar atividades que incluíssem a audição e a análise de rap - a partir das letras e dos arranjos musicais que configuram as bases de rap nacional, tais como Racionais MC's, Facção Central, Criolo, entre outros. Ao longo das oficinas, os alunos produziram coletivamente letras, fanzines, criaram bases rítmicas com a utilização de instrumentos de percussão e compuseram rap, além de participar de discussões em sala de aula provocadas por "temas geradores" inspirados pelas temáticas abordadas nas letras, entre outras atividades.

Essas oficinas fizeram parte de um amplo Projeto de Pesquisa de Políticas Públicas intitulado “Rappers, os novos mensageiros urbanos na periferia de São Paulo: 
a contestação estético-musical que emancipa e educa”4, coordenado pela professora doutora Mônica do Amaral, envolvendo diversos pesquisadores. As oficinas ocorreram na ONG Casa do Zezinho, situada no bairro do Capão Redondo, entre os anos de 2OII e 20I2, como também na Escola Municipal de Ensino Fundamental Desembargador Amorim Lima, situada no bairro do Butantã, no ano de 2013.

O principal objetivo das atividades realizadas com os jovens na faixa etária de I3 a I5 anos foi problematizar o sujeito periférico e marginalizado pelo viés histórico e social a partir do qual o rap nacional configura seu discurso para que os alunos pensassem criticamente sobre a própria condição social e existencial. A metodologia empregada foi desenvolvida ao longo das oficinas, de acordo com as demandas surgidas a cada debate com os alunos, que, por sua vez, faziam emergir determinadas questões sociais e subjetivas relacionadas ao universo particular do jovem e sua interação com o mundo exterior.

Para introduzirmos a discussão em torno do rap nacional, é necessário expor brevemente os principais aspectos que contribuíram para o surgimento do hip-hop - manifestação artística da qual o rap faz parte, que ocorreu inicialmente no Bronx, condado de Nova York (EUA), na década de I970, motivado pelo sofrimento de indivíduos afro-americanos que foram duramente atingidos pelas políticas públicas de urbanização adotadas e ações policiais. Como estratégia de luta pela afirmação de sua identidade e cultura, os jovens afro-americanos recorreram às artes do hip-hop como arma para denunciar as ações discriminatórias e para demarcar seus territórios nos bairros de Nova York. No Brasil, sua chegada foi impulsionada por necessidades sociais e culturais da juventude negra de São Paulo da década de I980.

No Brasil, a chegada da black music, especificamente o soul, antecipou a entrada do rap, influenciando os "rappers da velha escola do hip-hop"s. De acordo com Rocha, Domenich e Casseano, os bailes foram os primeiros a reunir a juventude negra de São Paulo, "promovidos principalmente pela Chic Show durante os anos 70". O rap nacional começou a ser disseminado no Brasil, principalmente no centro de São Paulo, na década de I980, por meio de encontros de dançarinos de break e integrantes do movimento hip-hop, que ocorriam no largo São Bento e nas galerias da rua 24 de Maio. Além de dançar, os jovens trocavam LPs ou fitas cassete e formavam duplas ou grupos de rap4. A chegada do hip-hop no Brasil na década de I980 foi essencial para o surgimento de ações afirmativas referentes à valorização do jovem afrodescendente, como nos casos das posses, que, de acordo com Contier, constituíram-se da reunião "de dois ou mais grupos de rap, formando uma turma para desenvolver ações sociais na sua comunidade"?.

4 Projeto de Políticas Públicas financiado pela Fapesp no Io/52002-9. Vigência: Io de fevereiro de 20II a 3I de janeiro de 20I4.

5 ROCHA, Janaína; DOMENICH, Mirella; CASSEANO, Patrícia. Hip-hop: a periferia grita. São Paulo: Fundação Perseu Abramo, 200I. p. I30.

6 Ibidem.

7 CONTIER, Arnaldo Daraya. O rap brasileiro e os Racionais MC's. In: SIMPÓSIO INTERNACIONAL DO ADOLESCENTE. An. I Simp. Internacional do Adolescente May.2005. p. 7. Disponível em: <http://www.proceedings. scielo.br/scielo.php?pid=MSCo000000082005000I000Io\&script=sci_arttext $\rangle$. Acesso em: 24 fev. 2015. 
O rap nacional caracteriza-se por três fases distintas, delineadas entre seu surgimento e as produções atuais. A primeira fase se caracteriza pelo seu discurso ideologicamente menos aguerrido em relação às fases posteriores, visto que os jovens da periferia, inicialmente, queriam se divertir e dançar nas ruas do centro da cidade. Mas esses encontros públicos já prenunciavam uma movimentação da juventude negra em busca de seus territórios na cidade de São Paulo. A segunda e a terceira fases recebem maior atenção em razão do discurso adotado em ambas, que se mostra mais comprometido ideologicamente com as causas sociais e denuncia a situação social de abandono do jovem afrodescendente. Sobre esse assunto, Fonseca ${ }^{8}$ destacou algumas características referentes à segunda fase, cuja narrativa denuncia o drama social dos indivíduos socialmente vulneráveis: "alguns núcleos parecem ser mais característicos de determinadas fases, a exemplo do que se refere à baixa expectativa de vida de quem é pobre, afrodescendente e vive em locais violentos" dessa segunda fase o grupo Racionais MC's e o rapper Sabotage, entre outros.

Ao se referir a essa segunda fase do rap nacional, a autora salienta um importante aspecto explorado em nossa pesquisa - a temática recorrente nas letras dos grupos surgidos no final dos anos I980 e início dos I990, caracterizada por denunciar esse sujeito periférico, afrodescendente, que convive cotidianamente com a violência.

Nesse sentido, as ideias desenvolvidas por Axel Honneth ${ }^{\text {IO }}$ a propósito da "luta pelo reconhecimento" como meio de fortalecer a identidade individual e coletiva do sujeito que tem o reconhecimento denegado tem nos auxiliado a analisar os resultados obtidos em nossas oficinas, como também a pensar na questão da afirmação da identidade do jovem afrodescendente e morador das periferias. Suas reflexões a propósito do déficit sociológico da "teoria crítica" também deram suporte à reflexão que vimos desenvolvendo a respeito dos problemas referentes aos jovens que são discriminados por questões histórico-raciais. Recorremos ainda à crítica de Adorno e Horkheimer à indústria cultural e sua hegemonia mercadológica com fins de cooptação da consciência das massas, bem como devido à sua capacidade de "habituar os sentidos" acerca da emancipação crítica do sujeito a partir dos processos de formação no ensino escolar.

Entretanto, é preciso trazer essa discussão para o contexto histórico que vivemos com a chegada da pós-modernidade. De acordo com o pensamento de Gilles Lipovetsky, a noção de pós-modernidade, surgida no final dos anos 1970,

8 FONSECA, Ana Silvia A. da. Versos violentamente pacíficos: o rap no currículo escolar. Tese (Doutorado). Instituto de Estudos da Linguagem, Universidade Estadual de Campinas, Campinas, 20 II.

9 Ibidem, p. I54.

Io HONNETH, Axel. Luta por reconhecimento: a gramática moral dos conflitos sociais. Trad. Luiz Repa. São Paulo: Editora 34, 2003.

II ADORNO, T. W.; HORKHEIMER, M. Dialética do esclarecimento: fragmentos filosóficos. Rio de Janeiro: Jorge Zahar, 2006, p. II4.

I2 ADORNO, T. W. Educação e emancipação. Trad. Wolfgang Leo Maar. Rio de Janeiro: Paz e Terra, I995. 
sugeria a ideia de "uma temporalidade dominada pelo precário e pelo efêmero" I3. A pós-modernidade é envolta "numa forma de sedução, ligada à individualização das condições de vida, ao culto do eu e das felicidades privadas" ${ }^{\text {"4 }}$. As transformações ocorridas de acordo com a lógica evolutiva da sociedade ou, como argumentou Hall, mais precisamente, segundo o "processo de mudança conhecido como "globalização"זs, atingem profundamente o jovem afrodescendente ao definir seu lugar dentro de uma estrutura socialmente desigual. Esse fenômeno ocorre em decorrência de aspectos raciais e históricos, que obrigam o jovem afrodescendente a buscar novas estratégias de enfrentamento da segregação social e espacial que lhe é imposta. Esse jovem se vê excluído da sociedade de consumo e, ao mesmo tempo, é, cada vez mais, assediado pela indústria cultural. Tais injunções podem tornar esse jovem vulnerável à criminalidade, levando-o a acreditar que será possível, por meio desse consumo, escapar da invisibilidade a que está sujeito em uma sociedade excludente.

Tais transformações na sociedade, que incidem no comportamento dos jovens, bem como nossas experiências com o rap em sala de aula, levaram-nos a considerar que o enfrentamento crítico dessa realidade pode ocorrer no ambiente escolar, como meio de aprofundar e desmitificar a análise das origens do racismo. Ao levar para a sala de aula as temáticas abordadas por rappers de diferentes fases, tais como Racionais MC's e Criolo, entre outros, buscamos percorrer, ao longo das oficinas, as incidências do passado escravocrata na vida na periferia. Nosso objetivo foi pautado pela necessidade de recontar essa história de modo aprofundado, para que fosse possível desfazer as marcas atribuídas ao indivíduo negro pelas formas de dominação originadas do preconceito racial perpetuado ao longo das transformações sociais. E o fizemos, recontando-a de modo que propiciasse a esse sujeito segregado, compreendido como "efeito colateral ${ }^{16}$ do sistema, o reconhecimento recíproco, que se efetua a partir de suas três formas, de acordo com Honneth: do amor, do direito e da solidariedade ${ }^{\mathrm{I} 7}$.

\section{EXPERIÊNCIAS EM SALA DE AULA: ORALIDADE, POESIA E RIMAS}

Nas oficinas de rap e letramento, propusemo-nos a pensar sobre outros caminhos do letramento, investigando a possibilidade de trazer para dentro da sala de aula conteúdos, assuntos e reflexões ligados aos interesses e necessidades demonstrados pelos jovens em suas experiências na periferia, fortemente marcadas pela tradição oral, de modo que torne relevante e significativo o processo de escolarização.

O trabalho envolveu a ideia de letramento como um processo sócio-histórico,

I4 LIPOVETSKY, Gilles. Os tempos hipermodernos. São Paulo: Editora Barcelona, 2004, p. 5I.

I5 Ibidem, p. 64 .

I6 HALL, Stuart. A identidade cultural na pós-modernidade. Rio de Janeiro: Lamparina, 20I4, p. I2.

I7 Trecho da letra de "Capítulo 4 versículo 3", do álbum Sobrevivendo no inferno, de I997. Cosa Nostra fonográfica. I997. I CD (72 min). Faixa 3 (8’o9). Digital estéreo.

I8 HONNETH, Axel, op. cit, p. I54. 
inserido nas práticas e usos culturais da língua produzidos em determinado contexto, segundo o qual se considera a escrita e a oralidade como atividades centrais na interação verbal. De acordo com essa perspectiva, entende-se que as práticas e usos sociais da língua encontram-se atravessadas por atividades discursivas concebidas como eventos de letramento ${ }^{\mathrm{I}}$, dos quais participam muitos indivíduos, alfabetizados ou não.

Partimos da hipótese de que, por meio do rap e da forte presença da oralidade nele contida, torna-se possível alimentar e enriquecer os conhecimentos da juventude urbana a respeito da linguagem, possibilitando uma entrada na escrita mais significativa e relevante do ponto de vista cultural.

Nesse sentido, o objeto de estudo deixa de ser a língua em si para centrar-se sobre os discursos e as práticas culturais que embasam a língua em uso. O que fundamenta essa ideia é a condição de produção do discurso, com ênfase no modo como se dá a articulação entre os processos discursivos e a língua, dos quais participam o sujeito e a história. É sobre uma base linguística que se desenvolve o discurso, que, por sua vez, traduz uma ideologia que representa todo um complexo dominante de produção de sentidos.

A face poética do movimento hip-hop está presente na formação discursiva dos jovens, especialmente entre os menos favorecidos, uma vez que as letras fazem parte de seu cotidiano, constituindo-se em verdadeiras crônicas que narram situações vividas na comunidade, auxiliando-os a compreender melhor a sociedade em que estão inseridos, além de entremearem as experiências linguísticas construídas nas situações comunicativas concretas. São ritmos, sons, batidas, rimas e poesias que contribuem para a formação e a ampliação do repertório linguístico dos jovens, por meio dos quais é possível interpretar o significado da escolha de cada palavra na composição de um verso e debater temas próximos da realidade de quem mora na periferia, mobilizando-os a se interessarem por outros textos.

Nossa pesquisa consistiu, basicamente, na realização de oficinas com aos jovens, explorando toda a interdiscursividade do rap, ou seja, a face poética do movimento hip-hop. Planejamos 25 encontros, de aproximadamente uma hora e meia cada um, durante o ano de 2012 (março a novembro), com jovens entre I3 e I5 anos, que cursavam desde as séries finais do ensino fundamental II ( $7^{\circ}, 8^{\circ}$ e $9^{\circ}$ anos) até a série inicial do ensino médio ( $\mathrm{I}^{\circ}$ ano).

No primeiro semestre, foram desenvolvidas atividades relativas à contextualização do hip-hop como expressão estética de contestação política, social e econômica, abordando o percurso histórico traçado pelo movimento nos Estados Unidos e no Brasil, em que ocorreram desdobramentos bastante importantes do ponto de vista cultural e político, particularmente entre os jovens oriundos das regiões periféricas das grandes metrópoles.

No segundo semestre, as oficinas tiveram um enfoque mais específico em torno das habilidades de escrita. Para tanto, foram organizados encontros centrados na ampliação do repertório dos alunos a respeito dos recursos estéticos utilizados

I9 O termo é empregado por Angela B. Kleiman no livro Os significados do letramento: uma nova perspectiva sobre a prática social da escrita. Campinas: Mercado das Letras, 1995. 
pelos rappers na composição da música, que tem, entre outras características, forte apelo político. Os principais representantes do rap nacional foram explorados, e as letras tornaram-se objeto de estudo e reflexão do grupo. Propusemos, entre outras atividades, uma visita ao Museu da Língua Portuguesa, a leitura de entrevistas e análise de documentários de rappers brasileiros e a construção de um fanzine revista bastante utilizada pelo movimento hip-hop para a divulgação de ideias, assim como shows, eventos, entre outros - a fim de registrar os raps de autoria produzidos pelos jovens no decorrer dos últimos encontros.

A partir do levantamento das principais necessidades apresentadas pelos jovens em relação ao letramento, inspiramo-nos nas ideias sustentadas pelos

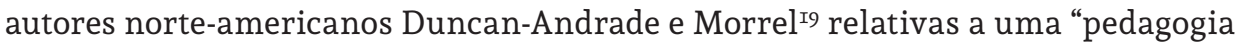
culturalmente relevante”, para planejar as nossas intervenções. Segundo eles, as escolas precisam enfrentar o desafio de propor um mundo mais justo do ponto de vista social, empregando práticas menos conservadoras, principalmente no tocante ao ensino público, devendo romper com o fracasso produzido pela própria estrutura social opressiva. Conclui-se que sejam as maiores vítimas desse sistema os jovens pobres e negros estadunidenses.

O quadro de exclusão escolar, para os autores, é possível de ser revertido à medida que seja oferecido ao aluno um conhecimento relevante do ponto de vista cultural, econômico, político e ideológico, que será responsável por promover uma identificação dos jovens com a escola e uma atribuição de sentido à escolarização. O jovem precisa entender a escola como uma instituição parceira da comunidade, na qual sua identidade e os conhecimentos construídos nas experiências coletivas poderão ser preservados.

De acordo com Duncan-Andrade e Morrel, é fundamental que a escola estabeleça um diálogo com a comunidade e que a pedagogia e ações didáticas tenham como base o vínculo com a cultura local, sem pretender substituí-las pela cultura dominante, responsável pelas exclusões escolares vividas pelos jovens urbanos:

Para ser eficaz, o movimento de reforma da educação urbana deve começar a desenvolver parcerias com as comunidades de modo que ofereça aos jovens a oportunidade de serem bem-sucedidos no espaço escolar, mantendo suas identidades enquanto juventude urbana. Este modelo de educação centra-se na concepção de uma cultura urbana escolar, de currículo e pedagogia, que identifica o conhecimento dos alunos de áreas urbanas como bens culturais e não como algo a ser substituído. A maneira particular e única de vida da juventude urbana merece um sistema de educação que realize dois objetivos em conjunto: a preparação para enfrentar as condições de desigualdade social e econômica em suas vidas diárias e o acesso aos letramentos acadêmicos (computacional e linguística) de modo que permita que a inserção escolar seja uma opção realista ${ }^{20}$.

20 DUNCAN-ANDRADE, Jeffrey M.; MORREL, Ernest. The art of critical pedagogy: possibilities for moving from theory to practice in urban schools. New York: Peter Lang, 2008.

2I Ibidem, p. 8 (tradução nossa). 
O currículo deve refletir a vida dos jovens, seus conhecimentos prévios obtidos nas ruas, por meio das tradições culturais familiares, na cultura juvenil (tendo o hip-hop como modelo) e na própria mídia. A escola deve configurar-se como um espaço privilegiado de formação de novas habilidades acadêmicas, bem como de construção de consciência crítica acerca dos caminhos e estratégias de resistência e emancipação políticas, de modo que mudanças possam ser produzidas contra as desigualdades sociais e raciais que pesam sobre a vida dos alunos.

Pensar as relações entre o letramento - entendido como um processo sócio-histórico de construção de discursos e práticas de leitura e escrita - e o rap, no contexto de uma pedagogia culturalmente relevante, possibilita a abertura de uma discussão a respeito da própria educação e a necessidade de transformação das práticas escolares a fim de que realmente se coloquem a serviço das necessidades dos alunos menos favorecidos. O discurso do rap entra na escola como um espaço do contradiscurso, de resistência e de crítica ao sistema educacional vigente, concebido como um agente de reprodução de um sistema de dominação.

\section{NA ORALIDAdE DO RAP: A VOZ E A VEZ DA PERIFERIA}

Ampliando a discussão e transpondo a reflexão para o campo da linguagem, observamos que as experiências orais que se aproximam da música, todo o repertório linguístico produzido pela escuta corriqueira de raps nas comunidades, constituem-se em conhecimentos que não são valorizados pelos padrões escolares, uma vez que suas letras são consideradas pobres, sem a qualidade poética presente em outros gêneros, inclusive musicais. Tais pressupostos, orientados por um tipo de letramento que desconhece o funcionamento social da linguagem, legitimam o desenvolvimento de habilidades de escrita e leitura de livros ou gêneros do discurso que, muitas vezes, não permitem o aprofundamento dos sentidos do texto ou a descoberta dos poderes da escrita, muito menos dizem algo significativo aos jovens urbanos da periferia. A discrepância entre a cultura escolar e a cultura local pode ser identificada, então, nessa distância e falta de diálogo presentes no letramento idealizado pela escola.

Desse modo, tomamos como base os conhecimentos advindos da história da escrita, particularmente as contribuições teóricas de Havelock ${ }^{2 \mathrm{I}}$, que apontam as inter-relações existentes entre a oralidade e a escrita, essenciais para se pensar em propostas de letramento alimentadas pela força da oralidade do rap.

Entre os gregos, até o século 700 a.C., era comum o uso da oralidade, pautada em situações cotidianas, em audiência pública, no emprego coletivo da linguagem. A sociedade fundamentava-se na cultura oral, na comunicação de mensagens por meio da recitação poética, na transmissão da linguagem geração após geração, na estruturação formular das ideias e pensamentos, assim como na potencialidade mnemônica da arte verbal; enfim, uma série de práticas socioculturais em que prevalecia a oralidade e que antecederam a construção da escrita e a criação do

22 HAVELOCK, Eric. A equação oralidade-cultura-escrita: uma fórmula para a mente moderna. In: OLSON, David R.; TORRANCE, Nancy. Cultura escrita e oralidade. São Paulo: Ática, I995. 
alfabeto. Os rapsodo ${ }^{22}$ figuravam entre as aldeias recitando versos, comunicando, narrando e descrevendo os fatos vividos pela comunidade. A origem grega da palavra, inclusive, remonta à ideia de recitação:

As convenções comuns da língua que se acham codificadas em nossos cérebros são acústicas, não visuais. A capacidade de pensar do homem está biologicamente relacionada com sua aptidão para falar, para estabelecer comunicação através do discurso oral, em qualquer dialeto que seu grupo linguístico tenha escolhido para seu uso, isto é, para o fazer compartir entre seus membros ${ }^{23}$.

Nas culturas orais, é comum identificar o uso de regras formulares na composição de poesias e versos. O ritmo, a métrica, a rima, as repetições, as aliterações, as assonâncias, garantem a escuta atenta e a recordação do que é ouvido, do que é narrado, de modo que a mensagem possa ser estabilizada numa expressão capaz de ser fixada pela comunidade.

Mais do que a prosa, a poesia apresenta o poder expressivo da memorização e da recitação, aspectos acentuadamente necessários às práticas orais de linguagem.

Numa cultura oral primária, para resolver efetivamente o problema da retenção e da recuperação do pensamento cuidadosamente articulado, é preciso exercê-lo segundo padrões mnemônicos, moldados para uma pronta repetição oral. O pensamento deve surgir em padrões fortemente rítmicos, equilibrados, em repetições ou antíteses, em aliterações e assonâncias, em expressões epitéticas ou outras expressões formulares, em conjuntos temáticos padronizados (a assembleia, a refeição, o duelo, o "ajudante" do herói e assim por diante), em provérbios que são constantemente ouvidos por todos, de forma a vir prontamente ao espírito, e que são eles próprios modelados para a retenção e a rápida recordação - ou em outra forma mnemônica ${ }^{22}$.

O contínuo de expressão verbal entre a oralidade e a escrita nos remete ao encontro da ontogênese e da filogênese. A fala é algo natural ao sujeito, ligada à formação de sua consciência. Faz parte do desenvolvimento humano falar, ouvir a palavra antes de vê-la escrita no ato da leitura; a palavra falada deu origem e continua conferindo sentido à palavra escrita, assim como ocorreu na história da humanidade, em sociedades nas quais a palavra era falada, as histórias eram contadas, os provérbios, as preces e as expressões formulares ensinadas oralmente, memorizadas, reproduzidas, recriadas, a depender do contexto de seu uso.

O rap não apenas abre o caminho para a rememoração do valor da oralidade em uma sociedade letrada como provoca o encontro com toda a ancestralidade africana presente nas comunidades fortemente marcadas pela tradição oral, que também

23 O significado do termo grego "recitar" é rhapsoidein, "costurar cantos" (rhaptein, costurar); oide, canto. ONG, Walter J. Oralidade e cultura escrita: a tecnologização da palavra. Campinas: Papirus, I998, p. 32.

24 HAVELOCK, Eric. A revolução da escrita na Grécia e suas consequências culturais. São Paulo: Editora da Universidade Estadual Paulista; Rio de Janeiro: Paz e Terra, I996, p. 55.

25 - ONG, Walter J., op.cit., p.45 
fizeram história por meio da figura dos griots, sábios que circulavam pelas aldeias, transmitindo conhecimentos e formando a população pela palavra.

Os rappers contemporâneos podem ser comparados aos griots africanos ao narrarem experiências coletivas, difundindo o seu discurso crítico e contestador, além de atribuírem sentido às práticas sociais vividas na periferia, dando voz a uma parcela da população que permanece excluída da produção do conhecimento, principalmente, letrado.

Como na Grécia Antiga, os griots, valendo-se das fórmulas, da arte das perífrases, das histórias narradas segundo técnicas de dicção e ritmos próprios da língua, faziam-se escutar em sua palavra contando fatos e situações sociais por intermédio de lendas que divertiam o público, mas que mantinham em segredo certos sentidos. Por meio dos griots, de sua oralidade e de sua memória, a história e a sabedoria de um povo foram mantidas vivas através das gerações.

Segundo Niane ${ }^{24}$, a maestria da arte de falar dos griots consistiu em perpetuar na memória dos homens os segredos seculares, além de preservar nomes de reis e histórias de reinos, a relação com o sistema religioso e as divindades, fatos e fenômenos da vida, perante as novas gerações, enfim, todo um saber que representa um verdadeiro legado da história ancestral dos povos negros africanos, que não foi contada em livros e tampouco arquivada por qualquer sistema de escrita, mas que foi preservada como tesouro por intermédio da transmissão oral.

O Ocidente ensinou-nos, infelizmente, a desprezar as fontes orais em matéria de História sendo, por isso, considerado como sem fundamento tudo o que não esteja escrito, o preto no branco. É por essa razão que, mesmo entre os intelectuais africanos, existem alguns tão limitados, a ponto de verem com desprezo os documentos "falados" que são os griots, e de suporem que nada - ou quase nada - sabemos de nosso passado, por falta de documentos escritos. Com isso, eles provam simplesmente que conhecem seu próprio país somente através dos brancos ${ }^{25}$.

A oralidade transforma-se em um depositário de valores e tradições que ultrapassam os limites da escrita, do registro, pois o ensinamento não está presente no documento escrito, mas no jeito de falar, no modo de dizer, na forma como se fala, nos modos de enunciação. Os griots acreditam que a palavra escrita é considerada apenas uma espécie de figuração da palavra, não a palavra em si. Segundo essa tradição, a palavra escrita pode ser adulterada, manipulada, já a palavra falada é carregada de honestidade porque a forma de expressão do falar está pautada pela oralidade.

Transgredindo, assim, os padrões normativos da língua, que tanto desvalorizam o conhecimento linguístico e a formação discursiva dos alunos "marginalizados", o rap propicia, como faziam os griots, por meio da oralidade formular o enriquecimento da escrita e a entrada culturalmente relevante do jovem urbano da periferia no mundo letrado, sugerindo um movimento inverso à lógica proposta pela escola, na qual a

26 NIANE, Djibril T. Sundjata ou A epopeia mandinga: romance. São Paulo: Ática, I982.

27 Ibidem, p. 7. 
escrita impõe-se e superpõe-se à oralidade, discriminando as culturas populares e de massa. De acordo com nossa concepção de letramento, é imprescindível que a escrita seja apresentada, não de maneira unívoca, mas como um dos modos de expressão de sentidos.

Passemos, então, ao modo como concebemos a estética musical do rap e sua fundamental importância para a formação dos jovens moradores da periferia.

\section{Estética do RAP E SUA RELEVÂNCIA PARA A AFIRMAÇÃo dA IDENTIDADE DO ADOLESCENTE AFRODESCENDENTE}

Neste item, abordaremos alguns resultados obtidos a partir das experiências musicais com ênfase no rap, especificamente em sua estética musical, desenvolvidas em oficinas que se destinaram a jovens de baixa renda e alunos do ensino fundamental da rede pública de ensino. A metodologia adotada pautou-se pelo objetivo de problematizar com os jovens o processo de cooptação da escuta efetuado pela indústria cultural, e de remetê-los às suas raízes históricas e culturais por meio da exploração, dos aspectos musicais e do discurso do rap, especificamente os produzidos pelos Racionais MC's. Nesse sentido, as atividades desenvolvidas com os jovens incluíam desde a improvisação musical livre com utilização de instrumentos de percussão de origem afro-indígena, audição de bases de rap nacional, análise de letras seguidas de discussão, até a criação de letras e composições de rap pelos próprios alunos.

A primeira etapa da pesquisa de campo da qual fizeram parte as oficinas ocorreu na ONG Casa do Zezinho, situada no Capão Redondo, zona sul da cidade de São Paulo, nos anos de 2011 e 20I2. A segunda etapa ocorreu na EMEF Desembargador Amorim Lima, situada no Butantã, zona oeste de São Paulo, no segundo semestre de 20I3. Embora cada etapa tenha se norteado pelo mesmo eixo teórico-metodológico, apresentaram resultados e aproveitamentos muito distintos entre si.

Durante a realização das oficinas, os jovens também tiveram contato com músicas que não faziam parte do repertório a que estavam habituados, tais como música dodecafônica e minimalista. O objetivo era chamar a atenção dos jovens para a diversidade de timbres e combinações rítmico-melódicas que tais gêneros musicais traziam em suas configurações estéticas. Os jovens se apropriaram de diferentes ideias musicais a partir do contato com esse material sonoro que se dava por meio das audições. Esse processo teve início quando passaram a diferenciar nas audições os timbres e instrumentos, como também a identificar as combinações rítmicas, dissonâncias e tantos outros aspectos estéticos sobre os quais se configuram as bases de rap e outros gêneros musicais mencionados.

O rap dos Racionais MC's foi nosso principal objeto de estudo para a elaboração das atividades desenvolvidas nas oficinas por ser dotado de uma configuração estética muito peculiar, construída a partir de uma consistente articulação entre ritmo e palavra. A estética musical do rap se configura a partir do seu discurso, de modo que a construção dos arranjos das bases musicais complementa a temática abordada. Essa junção entre a música e o discurso atribui ao rap o potencial de fazer ressoar a tensão social que é explicitada pelas temáticas abordadas nas letras. 
O ritmo, assim como a letra, é parte essencial para a configuração estética do rap. Na música brasileira, o ritmo é um elemento predominante, pois foi uma importante herança da cultura africana. De acordo com Wisnik ${ }^{26}$, "a música europeia se juntou com a africana no território das Américas”, o que ocasionou o surgimento de múltiplas linguagens musicais, cujo fenômeno contribuiu para a prática de "experiências de tempo musical de uma grande complexidade e sutileza" ${ }^{27}$. Para o autor, o desenvolvimento da música inclui "democráticas mixagens", que, novamente, tendem para "o questionamento e a criação sobre o pulso, o tempo, o ritmo"28. Embora o autor tenha se referido principalmente à música contemporânea, destacamos mais uma vez a proeminência do ritmo no rap e como este se reinventa na pós-modernidade a partir da tecnologia. O rap aproxima-nos, por meio do ritmo imanente à sua estética, do passado africano presente na sua estrutura musical. De acordo com Béthune ${ }^{29}$, os recursos tecnológicos como o sample e o scratch empregados nas bases de rap fazem ressoar a tradição dos tambores afro-americanos ancestrais.

No rap dos Racionais MC's, o ritmo apresenta-se de modo contundente para sustentar as questões explicitadas pelas letras. As questões que tangem a vida do jovem afrodescendente e o meio social que o cerca, por serem duras e se originarem do sofrimento, influenciam o ritmo, assim como outros elementos que formam a estrutura musical, atribuindo-lhe um caráter aguerrido. Vejamos, como exemplo dessa realidade retratada, uma frase do rap "Da ponte pra cá", que diz: "cada favelado é um universo em crise". A frase reflete a relação entre a segregação social e seu efeito na subjetividade do sujeito "favelado". Observemos, do mesmo modo, em "Negro drama": o trecho "o drama da cadeia e favela, túmulo, sangue, sirene, choros e velas" denuncia os altos índices de violência envolvendo indivíduos negros. Na mesma letra, a segregação espacial que ocorre por questões raciais também é evidenciada - "eu recebi seu tic, quer dizer kit, de esgoto a céu aberto e parede madeirite". Na estética do rap, predomina a narrativa acerca dos efeitos e origens do preconceito racial, em contraposição a arranjos complexos ou clichês musicais que venham a dispersar a atenção do ouvinte. Apenas ritmo e denúncia. Como disseram os Racionais MC's, "minha palavra vale um tiro e eu tenho muita munição"so.

Durante o processo de elaboração das oficinas, buscamos desenvolver atividades que reunissem a linguagem do rap à criação musical realizada pelos alunos. Observamos que os jovens apresentavam grande empenho na tarefa de articular suas ideias com o ritmo de modo inventivo. Não é tarefa fácil criar rimas articuladas à construção das bases rítmicas, sendo essa habilidade, conhecida como flow, uma das principais características do estilo musical dos rappers. Mesmo assim, os jovens, aos poucos, foram se apropriando das palavras como forma de expressar suas ideias, que

\footnotetext{
28 WISNIK, José Miguel. O som e o sentido, uma outra história das músicas. São Paulo: Companhia das letras, 2009. p. 55 .

29 Ibidem.

30 Ibidem.

3I BÉTHUNE, Christian. Le rap: une esthétique hors de la loi. Paris: Autrement, 2003.

32 Trecho da letra do rap “Capítulo 4 versículo 3" do CD Sobrevivendo no inferno, dos Racionais MC's.
} 
adquiriram novas e infinitas possibilidades de interpretação, conforme avançavam nos debates em torno das temáticas abordadas nas letras de rap. Suas reflexões, expressas em palavras e rimas, passaram a ser construídas de modo articulado à dimensão sensorial imanente ao ritmo.

A estética do rap nos aproximou da realidade desse jovem afrodescendente por meio da recepção dos alunos e do compartilhamento de conhecimentos que ocorreram no decorrer das oficinas. Os adolescentes que participaram das oficinas, que, por sua vez, são sujeitos cujas subjetividades estão em processo de formação, não se identificavam com as práticas ideológicas e valores morais ensinados na escola, considerados por eles como algo do passado e que se perpetuava no presente. Tais significados, que até então estabeleciam uma ordem social pela via da doutrinação ou "culpabilização", não entram em contato com suas realidades envoltas pela sedução das novidades surgidas com a pós-modernidade. Em outras palavras, tais valores vêm sendo substituídos pela lógica do consumo intenso. Esse consumo dos jovens se resume ao vestuário induzido pela moda e alguns artigos tecnológicos, como celulares, por exemplo.

O consumismo intenso faz parte de um fenômeno denominado por Hall como "pós-moderno global", que se pauta por uma "multiplicidade de estilos", com "ênfase no efêmero, no flutuante, no impermanente e na diferença e no pluralismo cultural" ${ }^{3}$. Para o autor, "os fluxos culturais, entre as nações, e o consumismo global criam possibilidades de 'identidades partilhadas' - como 'consumidores' para os mesmos bens"32 entre outros exemplos. A globalização, segundo o autor, ao enfraquecer as identidades culturais regionais, pode produzir o efeito da "homogeneização cultural" 33 . Sobre a questão do consumo intenso como efeito da globalização, Lipovetsky salienta que a moda pode ser um importante caminho para a compreensão de comportamentos individuais que se refletem nos comportamentos de massa, incluindo os juvenis: "a moda é menos signo das ambições de classes do que a saída do mundo da tradição, é um desses espelhos onde se torna visível aquilo que faz nosso destino histórico mais singular: a negação do poder imemorial do passado tradicional, a febre moderna das novidades, a celebração do presente social"34.

A análise desse autor nos leva a compreender o jovem afrodescendente inserido neste mundo de apelo ao consumo, não apenas como sujeito influenciado pela mídia, mas como sujeito movido pelo desejo de transformação de sua realidade, visto que seu passado histórico ou recente é marcado pela dor provocada pela discriminação racial e social. Nesse sentido, as questões que o rap suscitou durante a realização das oficinas ultrapassaram os limites da estética musical e do fenômeno da reificação da escuta e se voltaram à questão do consumo, trazendo, para o centro da discussão, o jovem afrodescendente e morador das periferias.

Ao invés de partirmos do discurso do rap para suscitar questionamentos no

33 HALL, Stuart, op. cit., p. 42.

34 Ibidem.

35 Ibidem, p. 43 .

36 LIPOVETSKY, Gilles. O império do efêmero: a moda e seu destino nas sociedades modernas. São Paulo: Companhia das Letras, 2006, p. II. 
jovem, voltamo-nos para o sujeito sobre o qual se constitui esse discurso. Esses jovens mostraram-nos que suas identidades foram construídas a partir de inúmeros elementos exteriores, e não de um único "eu", indivisível. Os elementos constitutivos dessas identidades múltiplas e mutáveis, por sua vez, alteravam-se de acordo com as transformações sociais. Para compreendermos essa dimensão multifacetada da constituição subjetiva desses jovens, recorremos às ideias de Stuart Hall35 sobre a identidade e de como esta se forma e se modifica em meio aos "processos inconscientes" em jogo: "ela permanece sempre incompleta, está sempre 'em processo', sempre 'sendo formada" ${ }^{36}$. A identidade social do jovem se molda a partir da expectativa de como sua imagem é vista pelo outro. Baseando-se nesse "olhar do outro", Hall argumenta sobre a "falta de inteireza que é 'preenchida' a partir de nosso exterior, pelas formas através das quais nós imaginamos ser vistos por outros"37. Um exemplo desse discurso dentro do rap pode ser encontrado na primeira frase de Negro drama, dos Racionais MC's: "Negro drama entre o sucesso e a lama, dinheiro, problemas, inveja, luxo, fama”.

\section{(IN)CONCLUSÃO...}

O debate aqui proposto delineou algumas das muitas possibilidades de abordar a identidade dos jovens das periferias, mais especificamente a identidade dos afrodescendentes e sua constante tensão entre resistência e repressão, uma vez que, conforme Joaquim, "a trajetória da raça negra e da sua cultura no Brasil tem sido marcada pelo binômio repressão/resistência cultural"38.

Assim como a cultura, a educação tem desenvolvido um papel importante na superação desse binômio, pois há muito percebemos que as instituições educacionais formais, apesar da sua importância fundamental na formação dos alunos, não dão mais conta das subjetividades dos mesmos e muito menos das nuances da nova dinâmica social, que, apesar de nova, insiste em perpetuar o discurso e as práticas racistas, sexistas, homofóbicas, muitas vezes, justificadas pela inexperiência dos professores em lidar com tais questões.

Ao analisarmos a história do hip-hop no Brasil e a trajetória dos ícones dessa modalidade cultural, percebemos sua complexidade cultural e social. Compreendemos que o rap faz parte do universo simbólico dos jovens das periferias, cujas lideranças - figuradas pelos rappers - é que dão sentido às suas existências. É através do rap que esses "griots da periferia" preservam as tradições e reforçam a identidade afro-brasileira. São lideranças que adquirem importância ao reconhecer a força dos "manos" das comunidades nas lutas de resistência nas periferias. São

\footnotetext{
37 HALL, Stuart, op. cit., p. 24.

38 Ibidem.

39 Ibidem, p. 24-25.

40 JOAQUIM, Maria S. O papel da liderança religiosa feminina na construção da identidade negra. Rio de Janeiro: Pallas; São Paulo: Educ, 200I, p. 24.
} 
parte dessas comunidades, reconhecem-se como tais e sabem como expressar a dor e os abafados gritos de guerra dos jovens negros, herdeiros da diáspora do Atlântico.

Esse movimento provoca um sentimento de pertencimento nos jovens que nos leva a crer que o hip-hop possibilita o surgimento e a construção de uma identidade coletiva que fortalece os moradores das periferias e os ajuda a superar o processo desintegrador que os coloca à margem.

Nesse processo, está implícita uma luta política por justiça e reconhecimento. E o debate sobre reconhecimento, conforme Axel Honneth ${ }^{39}$, adquire importância substancial na atualidade, principalmente quando as identidades na contemporaneidade, a exemplo dos hip-hoppers, adquirem relevância, além de cultural, política.

Honneth procura analisar os conflitos existentes nos grupos sociais, denominados por ele de "historicamente prejudicados", a fim de entender como ocorre o processo de reconhecimento entre as minorias, e aponta a "luta pelo reconhecimento" como meio de fortalecer a identidade individual e coletiva que fora negada a esses sujeitos, o que nos aponta um caminho para a análise das culturas juvenis em consonância com a concepção igualitária do exercício da cidadania democrática, presente na voz desses griots contemporâneos e dos próprios jovens.

Nas oficinas realizadas nas instituições percebemos que, quando a tônica é o hip-hop, a postura dos alunos muda, eles demonstram que ao menos naquele momento sabem mais do que os professores, pois eles “conhecem" os rappers, sua trajetória, sabem do que eles estão falando, reconhecendo em suas músicas a narrativa da própria história, são "manos". É um duelo entre o saber acadêmico e a sabedoria popular, vivida e sentida no cotidiano desses alunos. Uma cultura forjada nas entrelinhas da história oficial.

Gilroy ${ }^{40}$ reforça esse ponto de vista ao afirmar que as pessoas comuns não necessitam de uma vanguarda intelectual para ajudá-las a falar ou para dizer a elas o que dizer. Repetidamente, dentro dessa cultura expressiva, são os músicos "periféricos" que se apresentam como símbolos vivos do valor da espontaneidade - e do improviso. Muitas vezes, isso não é nada mais do que questão de estilo4I ${ }^{4 \mathrm{I}}$ E estilo é o que não falta aos rappers.

Através desse projeto cultural nas escolas, comprovamos ser possível desenvolver o interesse dos jovens pela educação. Mas uma educação que leve em conta a herança cultural dos afrodescendentes e suas diferentes e difíceis histórias de vida. Por meio do rap, da estética e do letramento, é possível despertar em maior grau o interesse dos jovens pela escrita, pela leitura, pela história, cujas áreas de conhecimento darão o suporte para a construção de uma identidade amparada em dados históricos relevantes que os ajudará a construir caminhos de superação. Não se pode negar que o rap se tornou um dos elementos essenciais na construção da subjetividade dos jovens.

4 I HONNETH, Axel, op. cit.

42 GILROY, Paul. O Atlântico negro: modernidade e dupla consciência. Trad. Cid K. Moreira. São Paulo: Ed. 34; Rio de Janeiro: Universidade Candido Mendes, Centro de Estudos Afro-Asiáticos, 200I.

43 Ibidem, p. I69. 
Afirmamos que, conforme Gilroy, os diálogos intensos e muitas vezes amargos que acionam o movimento das artes negras oferecem um pequeno lembrete de que há um momento democrático, comunitário, sacralizado no uso de antífonas ${ }^{42}$, que simboliza e antecipa (mas não garante) relações sociais renovadas de não dominação. As fronteiras entre o eu e o outro são estabelecidas por meio de conversas como as propiciadas pelo rap entre o eu racial fraturado, incompleto e inacabado, e os outros. A antífona é a estrutura que abriga esses encontros essenciais ${ }^{43}$.

O hip-hop, por constituir parte importante da cultura juvenil e expressar de forma contundente a força da palavra, da construção do discurso sociopolítico, pode ser mais bem aproveitado, pois ele, além de ser porta-voz de uma geração, através do rap, remete-nos ao enfrentamento de uma importante tensão social interposta pela dinâmica do ensino convencional da escrita e leitura nas escolas. É comprovado que a supremacia da linguagem escrita sobre a linguagem oral tem distanciado os jovens dos bancos escolares, os quais tanto têm afastado as culturas populares e de massa das propostas curriculares.

É necessário somar esforços com instituições sociais e artísticas para implementar uma formação por meio da qual o aluno atribua sentido ao seu processo de escolarização e possa partilhar seus saberes. Uma proposta que implica sair do modelo tradicional das salas de aula para outros espaços onde se aprenda com as batidas dos tambores, dos atabaques, dos berimbaus, das palmas das mãos, dos corpos a balançar e da livre criação.

E propor uma educação, como a que experimentamos nesse período - pautada por cantos falados e palavras rimadas -, em que os jovens se apropriem de seu espaço e consigam ver a escola como verdadeira parceira da comunidade, levando em conta os conhecimentos e experiências da coletividade.

Portanto, conforme constatamos e tantos outros estudiosos das culturas juvenis vêm observando, o currículo escolar deve refletir de forma mais ampla a vida dos jovens, seus conhecimentos prévios, formados nas ruas, nas tradições culturais familiares, na cultura juvenil e por meio da própria mídia. Cabe à escola repensar sua prática de ensino para não perder esses jovens, bem como incluir nos currículos novas metodologias de ensino que privilegiem a construção de uma consciência crítica e engajada politicamente. E assim, sem pretender concluir um assunto tão complexo, encerramos citando Oswaldo Montenegro 44: "Que a arte nos aponte uma resposta, mesmo que ela não saiba”.

44 Do grego antíphona, "som em resposta". Termo que deu origem à palavra anthem (na Inglaterra do século $\mathrm{XVI}$, versículo cantado antes e depois do Salmo, com resposta do coro, dividido em dois.

45 GILROY, Paul, op. cit., p. I68.

46 O trecho citado refere-se aos versos do poema "Metade", de Oswaldo Montenegro, escrito em junho de I975 e publicado no mesmo ano no libreto da peça João sem nome. A obra está devidamente editada na Warner/ Chappell Music. 
ANA CLAUDIA FLORINDO FERNANDES é professora multidisciplinar no ensino fundamental I. Mestre em Educação pelo Programa de Pós-Graduação em Educação da Faculdade de Educação da Universidade de São Paulo.

E-mail: anaflorindo@usp.br

RAQUEL MARTINS é bacharel em Música. Mestre em Educação pelo Programa de Pós-Graduação em Educação da Faculdade de Educação da Universidade de São Paulo.

E-mail: raquelproducaomusical@yahoo.com.br

ROSÂNGELA PAULINO DE OLIVEIRA é professora da Universidade Nove de Julho - Uninove. Doutora em Antropologia Cultural pelo Programa de Pós-Graduação em Ciências Sociais da Pontifícia Universidade Católica de São Paulo - PUC-SP. Integrante do grupo de pesquisa Multiculturalismo e Educação do Conselho Nacional de Desenvolvimento Científico e Tecnológico (CNPq).

E-mail: rose.paulino@uol.com.br

\section{REFERÊNCIAS BIBLIOGRÁFICAS}

ADÉKŌYÃ, Olúmúyiwá A. Yorùbá: tradição oral e história. São Paulo: Terceira Margem, I999.

ADORNO, T. W. Educação e emancipação. Trad. Wolfgang Leo Maar. Rio de Janeiro: Paz e Terra, I995.

ADORNO, T. W.; HORKHEIMER, M. Dialética do esclarecimento: fragmentos filosóficos. Rio de Janeiro: Jorge Zahar, 2006.

ALVES, César. Pergunte a quem conhece: Thaíde. [Com CD]. São Paulo: Labortexto, 2004.

BÉTHUNE, Christian. Le rap: une esthétique hors la loi. Paris: Autrement, 2003.

CONTIER, Arnaldo D. O rap brasileiro e os Racionais MC's. In: SIMPÓSIO INTERNACIONAL DO ADOLES-

CENTE. An. I Simp. Internacional do Adolescente May.2005. Disponível em: <http://www.proceedings. scielo.br/scielo.php?pid=MSC0000000082005000I000Io\&script=sci_arttext $\rangle$. Acesso em: 24 fev. 2015 .

DUNCAN-ANDRADE, Jeffrey M.; MORREL, Ernest. The art of critical pedagogy: possibilities for moving from theory to practice in urban schools. New York: Peter Lang, 2008.

FONSECA, Ana Silvia A. da. Versos violentamente pacíficos: o rap no currículo escolar. Tese (Doutorado), Instituto de Estudos da Linguagem, Universidade Estadual de Campinas, Campinas, 20II.

GILROY, Paul. O Atlântico negro: modernidade e dupla consciência. Trad. Cid Knipel Moreira. São Paulo:

Ed. 34; Rio de Janeiro: Universidade Candido Mendes, Centro de Estudos Afro-Asiáticos, $200 \mathrm{.}$ 
HALL, Stuart. A identidade cultural na pós-modernidade. Rio de Janeiro: Lamparina, 20I4.

HAVELOCK, Eric. A equação oralidade-cultura-escrita: uma fórmula para a mente moderna. In: OLSON, David R.; TORRANCE, Nancy. Cultura escrita e oralidade. São Paulo: Ática, I995. . A revolução da escrita na Grécia e suas consequências culturais. São Paulo: Editora da Universidade Estadual Paulista; Rio de Janeiro: Paz e Terra, I996.

HONNETH, Axel. Luta por reconhecimento: a gramática moral dos conflitos sociais. São Paulo: Editora 34, 2003.

JOAQUIM, Maria S. O papel da liderança religiosa feminina na construção da identidade negra. Rio de Janeiro: Pallas; São Paulo: Educ, 200I.

KLEIMAN, Angela B. Os significados do letramento: uma nova perspectiva sobre a prática social da escrita. Campinas: Mercado das Letras, I995.

LIPOVETSKY, Gilles. Os tempos hipermodernos. São Paulo: Editora Barcelona, 2004. . O império do efêmero: a moda e seu destino nas sociedades modernas. São Paulo: Companhia das Letras, 2006.

MARTINS, Rosana. Hip-hop: o estilo que ninguém segura. Santo André: ESETec, 2005.

MONTENEGRO, Oswaldo. Metade. In: MONTENEGRO, O. Libreto da peça João sem nome. Los Angeles: Warner/Chappell Music, I975.

NIANE, Djibril T. Sundjata ou A epopeia mandinga: romance. São Paulo: Ática, I982.

ONG, Walter J. Oralidade e cultura escrita: a tecnologização da palavra. Campinas: Papirus, I998.

PARRY, M. The collected papers of Milman Parry. Edited by A. Parry. Oxford: Oxford University Press (Clarendon Press), I97I.

ROCHA, Janaína; DOMENICH, Mirella; CASSEANO, Patrícia. Hip-hop: a periferia grita. São Paulo: Fundação Perseu Abramo, 200I.

WISNIK, José M. O some o sentido: uma outra história das músicas. São Paulo: Companhia das Letras, 2009. 